\title{
Optimal Endoscopic Treatment and Surveillance of Serrated Polyps
}

\author{
Vipin Gupta and James E. East \\ Translational Gastroenterology Unit and Oxford NIHR Biomedical Research Centre, Experimental Medicine Division, Nuffield Department of \\ Clinical Medicine, University of Oxford, John Radcliffe Hospital, Oxford, UK
}

Serrated polyps are considered precursor lesions that account for $15 \%$ to $30 \%$ of colorectal cancers, and they are overrepresented as a cause of interval cancers. They are difficult to detect and resect comprehensively; however, recent data suggest that high definition endoscopy, chromoendoscopy (via spray catheter, pump or orally), narrow band imaging, split-dose bowel preparation and a slower withdrawal (>6 minutes) can all improve detection. Cold snare resection is effective and safe for these lesions, including cold snare piecemeal endoscopic mucosal resection, which is likely to become the standard of care for lesions $>10 \mathrm{~mm}$ in size. Sessile serrated lesions $\geq 10 \mathrm{~mm}$ in size, those exhbiting dysplasia, or traditional serrated adenomas increase the chance of future advanced neoplasia. Thus, a consensus is emerging: a surveillance examination at 3 years should be recommended if these lesions are detected. Serrated lesions likely carry equivalent risk to adenomas, so future guidelines may consider serrated class lesions and adenomas together for risk stratification. Patients with serrated polyposis syndrome should undergo surveillance every 1 to 2 years once the coIon is cleared of larger lesions, and their first degree relatives should undergo screening every 5 years starting at age 40 . (Gut Liver 2020;14:423-429)

Key Words: Colorectal neoplasms; Serrated polyps; Endoscopic mucosal resection; Endoscopic submucosal dissection; Serrated polyposis syndrome

\section{INTRODUCTION}

Colorectal cancer (CRC) is one of the leading causes of mortality around the world. It is the fourth most common cancer worldwide accounting for $6.1 \%$ of total cancers diagnosed and second leading cause of cancer related death, after lung can- cer, in world. ${ }^{1}$ In the United Kingdom, bowel cancer is the 4th most common cancer accounting for 12\% of all new cancer diagnosis. Overall, serrated polyps contribute to $20 \%$ to $30 \%$ of sporadic CRCs. ${ }^{2}$ Although serrated lesions are thought to be less common in Asian populations, a number of studies from Korea and Hongkong have suggested similar rates to Western cohorts. ${ }^{3-5}$ Failure to detect sessile serrated lesions (SSL) is thought to be one of the reasons for interval $\mathrm{CRC}^{6}$ and the failure of screening colonoscopy in preventing right sided colon cancers. ${ }^{7}$ One of the reasons behind this is that SSL are difficult to detect or visualize during endoscopy due to flat shape and pale or translucent appearance ${ }^{8}$ and are often incompletely resected. ${ }^{9}$ These issues have implications on what should be the optimal endoscopic treatment and surveillance of serrated polyps which remains area of active research. Through this review, we attempt to address this contentious issue through available literature and evidence.

\section{SESSILE SERRATED POLYPS AND THEIR ENDOSCOPIC DETECTION}

Lesion of the serrated class include sessile serrated polyps (SSPs) along with hyperplasic polyps and traditional serrated adenomas form heterogeneous group. ${ }^{10}$ SSPs can be further characterized on basis on endoscopic, histological and molecular features. Endoscopic assessment of SSP is challenging. They are often subtle, pale in appearance and are frequently masked by mucous cap. ${ }^{11}$ Features suggestive of SSL rather than hyperplastic polyp include dark spots within pits, indistinct boarder, a cloud-like or bosselated surface and irregular shape. ${ }^{12,13}$ Dysplastic lesions have transition from flat to nodular, sessile or depressed area; type III-V pit pattern and NICE $2 .{ }^{14}$

They are more common in the right side of colon where less good preparation can make detection challenging. Detection can

\footnotetext{
Correspondence to: James E. East

Translational Gastroenterology Unit and Oxford NIHR Biomedical Research Centre, Experimental Medicine Division, Nuffield Department of Clinical Medicine, University of Oxford, John Radcliffe Hospital, Headley Way, Headington, Oxford OX3 9DU, UK

Tel: +44-1865-228753, Fax: +44-1865-228763, E-mail: james.east@ndm.ox.ac.uk

Received on June 15, 2019. Revised on July 26, 2019. Accepted on August 12, 2019. Published online October 8, 2019.

pISSN 1976-2283 eISSN 2005-1212 https://doi.org/10.5009/gnl19202

@ This is an Open Access article distributed under the terms of the Creative Commons Attribution Non-Commercial License (http://creativecommons.org/licenses/by-nc/4.0) which permits unrestricted non-commercial use, distribution, and reproduction in any medium, provided the original work is properly cited.
} 
Table 1. Interventions at Colonoscopy That May Improve Serrated Lesion Detection Rates

\begin{tabular}{lcl}
\hline \multicolumn{1}{c}{ Beneficial } & $\begin{array}{c}\text { May be } \\
\text { beneficial }\end{array}$ & \multicolumn{1}{c}{ No clear benefit } \\
\hline $\begin{array}{l}\text { Slower withdrawal }>6 \text { min } \\
\text { Chromoendoscopy }\end{array}$ & $\begin{array}{l}\text { Endocuff } \\
\text { G-EYE }\end{array}$ & $\begin{array}{l}\text { Antispasmodics } \\
\text { Good vs adequate bowel } \\
\text { High definition }\end{array}$ \\
Narrow-band imaging & & $\begin{array}{l}\text { Preparation } \\
\text { Wide angle and enhanced }\end{array}$ \\
Split dose bowel & mucosal views \\
preparation & Right colon retroflexion \\
\hline
\end{tabular}

Adapted from East JE, et al. Gut 2017;66:1181-1196. ${ }^{16}$

be improved by withdrawing slowly, using high definition colonoscope ${ }^{15}$ and chromoendoscopy (dye spray) (Table 1). ${ }^{16-18}$ Some early data suggests the use of Endocuff may support SSL (SSA/ P) detection with a 15\% detection rate with Endocuff versus a 3\% rate with standard colonoscopy $(\mathrm{p}=0.001) .{ }^{19} \mathrm{~A}$ colonoscope with a large balloon at the bending section which slows withdrawal and compresses folds (G-EYE colonoscope; Smart Medical Systems Ltd., Ra'anana, Israel) also improved serrated lesion detection rates in a large randomized controlled study ( $2.7 \%$ vs $0.8 \%$, $\mathrm{p}=0.036) .{ }^{20}$ A study that looked at narrow-band imaging (NBI; Olympus, Tokyo, Japan) for serrated polyp detection suggested a statistical trend toward improved detection with a mean number of serrated lesions proximal to the sigmoid of 0.51 with NBI versus 0.39 for white light $(\mathrm{p}=0.085) .{ }^{21}$ A subsequent metaanalysis of NBI for detection of non-adenomatous (serrated) lesions suggested significantly improved detection with either first or second generation "Bright" NBI. ${ }^{22}$ With increasing use of NBI, the Workgroup on Serrated Polyps and Polyposis (WASP)-has described classification (also called WASP) for distinguishing between hyperplastic and adenomatous/serrated polyps (Fig. 1). ${ }^{23}$ In WASP classification , criterion like "dark spots inside crypt" are more reliable than criterion "irregular shape." Also, it does not incorporate a commonly used criterion in practice, "mucus cap."

Although higher bowel preparation quality has previously not been shown to be associated with improved serrated lesion detection, a recent meta-analysis suggests that use of split dose bowel preparation does seem to improve serrated lesion detection relative risk of 2.48 (95\% confidence interval [CI], 1.21 to 5.09). ${ }^{24}$

\section{ENDOSCOPIC TREATMENT METHODS}

The choice of endoscopic resection for any polyp revolves around two principles; safety and recurrence. Recurrence depends heavily on completeness of endoscopic resection. Size more than $10 \mathrm{~mm}$ and SSP are two strongest predictors of incomplete endoscopic resection. ${ }^{9}$ Hence, removal of SSP of size

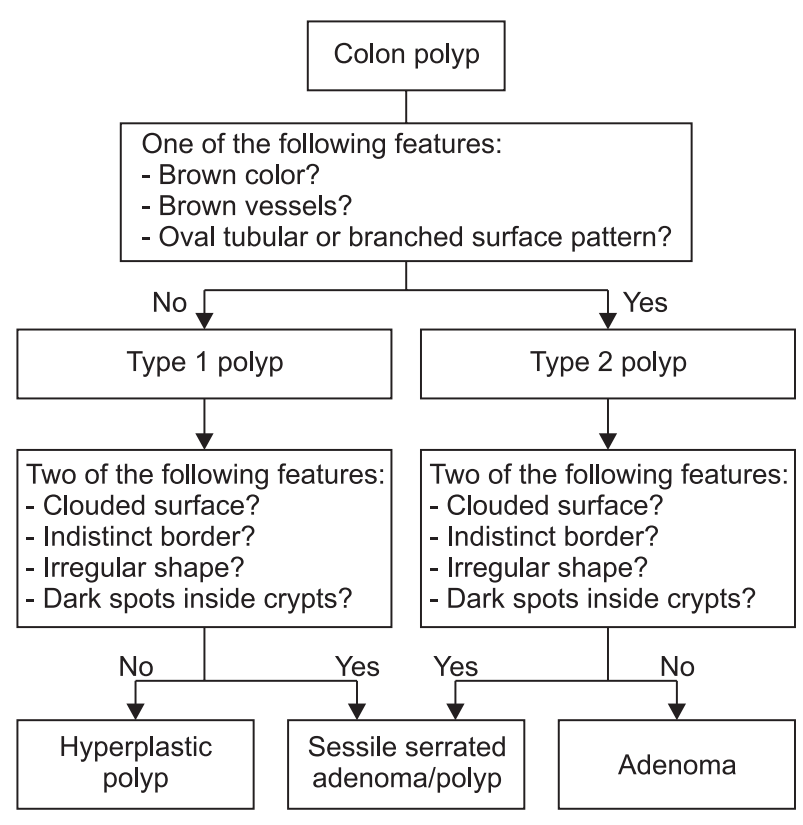

Fig. 1. Workgroup on Serrated Polyps and Polyposis (WASP) classification.

over $10 \mathrm{~mm}$ requires expertise. Cold snare polypectomy is the preferred method for removal of SSP less than $10 \mathrm{~mm}$. Relatively little data specific to serrated lesions is available; however in cases series of small polyps which are predominantly adenomatous, cold snaring is a very safe and efficacious method and performs better than cold forceps polypectomy method. ${ }^{25,26}$ Rates of complications with cold snare polypectomy are very low and intra procedural bleeding, 1.8\% in one large series, is usually controlled with injection or endoscopic clipping. ${ }^{17}$ Perforations, which are more of concern with hot snare, are exceptionally rare with cold snare. Majority of the bleed with cold snare are immediate and self-limiting.

Thin wire $(0.30 \mathrm{~mm})$ snares have been shown more effective than thick wire $(0.47 \mathrm{~mm})$ snares in achieving complete endoscopic and pathologic excision. Horiuchi et al. ${ }^{27}$ showed, in a prospective randomized controlled trial of 210 polyps, that thin wire snares have significantly more complete pathological resection as compared to thick wire snare (91\% vs 79\%, $\mathrm{p}=0.02$ ). In another study Din et al. ${ }^{28}$ showed there was significantly endoscopic complete resection $(90.2 \%$ vs $73.3 \%, p<0.05)$ and nonsignificant higher trend for complete pathological excision (73.3\% vs $65.2 \%, p=0.4)$ with thin wire snares. Injection can be helpful to help grasp some normal mucosa around the edges of these flat lesions to maximise chances of comprehensive resection, and adding methylene blue or indigo carmine to the injection fluid and provide contrast to see the edges of the lesion more clearly (Fig. 2). 

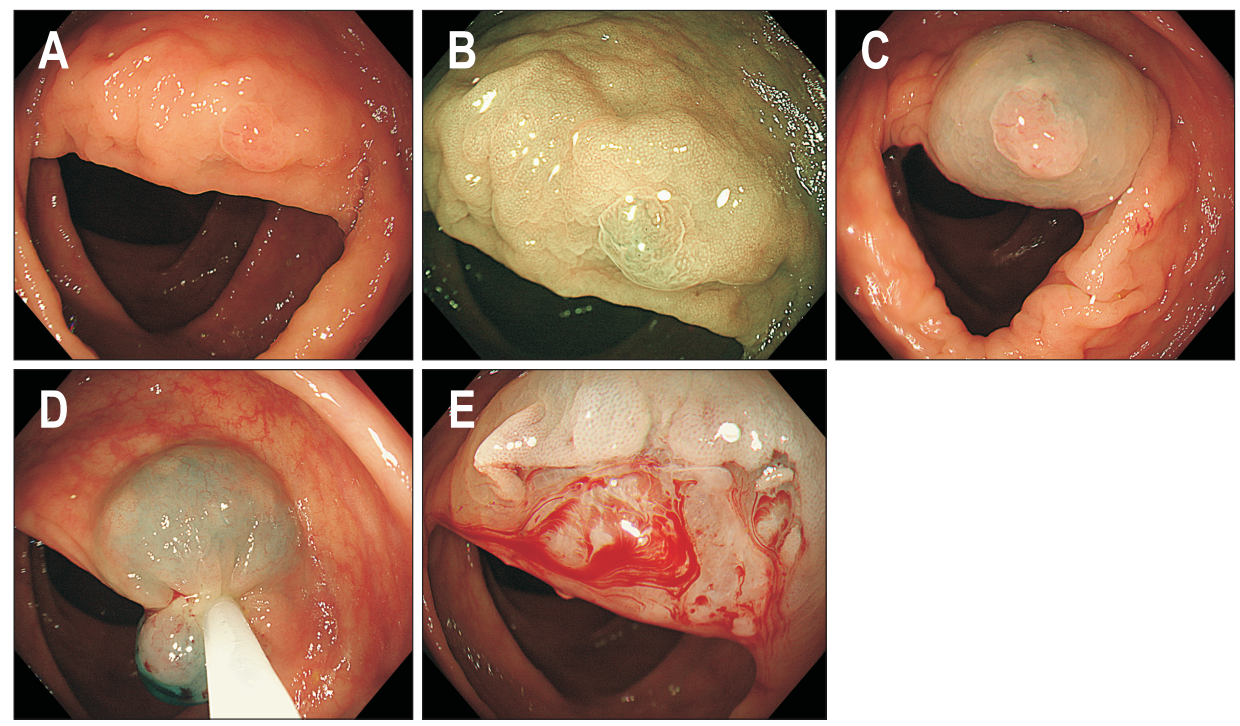

Fig. 2. Cold snare lift and endoscopic mucosal resection of small sessile serrated lesion. (A) A 5-mm serrated polyp observed in the ascending colon. (B) Lesion seen with narrowband imaging under magnification; note the small black dots within the pits, suggestive of a sessile serrated lesion. (C) Resected lesion with fluid. The specimen was stained with methylene blue as a contrast agent to clarify the lesion edges. (D) Lesion grasped with a thin wire cold snare. Note the additional normal mucosa snared to ensure complete excision. (E) Post-resection defect observed under magnification after washing. Note that normal mucosa can be clearly observed around the edges, confirming excision.

Table 2. Cold Snare Resection of Larger Serrated Lesions

\begin{tabular}{lccccc}
\hline \multicolumn{1}{c}{ Author (year) } & No. & Size, mm & Pathology & Complications & Recurrence, \% \\
\hline Tate et al. $(2018)^{34}$ & 34 & $10-35$ & SSP & None & None \\
Rameshshanker et al. (2018) & 29 & $10-30$ & SSP & None & 3.4 \\
Piraka et al. (2017) & 94 & $10-60$ & 75 TA/TVA & Clip $\times 1$ & 9.7 \\
& & & & & \\
\hline
\end{tabular}

SSP, sessile serrated polyp; TA, tubular adenomas; TVA, tubulo-villous adenoma.

\section{ENDOSCOPIC MUCOSAL RESECTION OF LARGE SER- RATED LESIONS}

For lesions greater than $10 \mathrm{~mm}$, endoscopic mucosal resection (EMR) is the preferred technique. It is important to carefully inspect larger lesion as they have more chance to have dysplasia which may appear as subtle change in surface of polyp in form of nodularity, elevation or depression with or without adenomatous pit pattern. ${ }^{29}$ EMR is safe and efficacious method of removing larger (>10 mm) SSPs. SSP s are easier to remove by endoscopic resection as compared to adenomas as they do not have submucosal fibrosis and are loosely attached to deeper layers making lifting easy after injection. Rao et al. ${ }^{30}$ showed, in a large cohort of $251 \mathrm{SSP}$ (>10 mm), EMR could safely remove polyps with only $3.6 \%$ recurrence rate after mean follow-up of $17.8 \pm 15.4$ months. All recurrences (median size, $4 \mathrm{~mm}$ ) could be managed by endoscopic resection.

In a large cohort of laterally spreading tumors (LST) $>20 \mathrm{~mm}$, Pellise et $a l^{31}$ showed EMR could successfully remove SSP as compared to adenomas with similar adverse events and less bleeding. The same study showed significantly lower rates of recurrence with SSP at 6 months (6.3\% vs 16.1\%) and 12 months (7.0\% vs 20.1\%) compared to adenomatous lesions. EMR does have associated complications which involve bleeding (1/10 to $1 / 30){ }^{32}$ perforation $(1 / 100)$ and post polypectomy syndrome
$(1 / 200) .{ }^{33}$ Given the risks of resection of flat lesion in the right colon, some authors have suggested that the risks of resection may outweigh the cancer prevention benefits; however, we would suggest that cold snare piecemeal EMR (pEMR) is a safe and effective way to resect these larger right sided serrated lesions. Three recent studies have reported cold snare pEMR data, with or without injection to lift the lesion, with acceptable rates of recurrence and low complication rates (Table 2), and it seems likely that cold snare pEMR will become the standard of care for resection of these lesions in the future. ${ }^{34-36}$

\section{ENDOSCOPIC SUBMUCOSAL DISSECTION OF LARGE SERRATED LESIONS}

Large SSLs are predominantly right sided, as compared to adenomatous LSTs) which have propensity for being left sided or rectal. The risk of recurrence in large SSLs is lower than equivalent adenomatous lesions, and the risk of invasive cancer is also lower for a lesion of equivalent size. ${ }^{30}$ Endoscopic submucosal dissection (ESD) has been described in management of large serrated lesion; ${ }^{37}$ however, it has its own technical challenges, e.g., the flap of SSLs is thin and floppy making it difficult to control using standard gravity-based positioning during ESD. Therefore the advantages of use of ESD for which are perhaps clearest for large rectal lesions where the risk of recurrence or invasion 
is high, and the consequences of a perforation are lower, are inverted for serrated lesions which are technically difficult to resect, occur in the thin walled right colon, and are low risk for recurrence or invasion. ${ }^{38-40}$ We therefore recommend cold snare pEMR for large SSLs, and would only consider ESD for a lesion assessed as high risk for early sub-mucosal invasion. Traditional serrated adenomas are morphologically much more similar to LSTs, are predominantly found in the rectum and may be good targets for ESD. In a large Korean cohort of SSP/adenoma with dysplasia/adenocarcinoma, ESD was used as resection method in $3.8 \%$ of patients for SSP $\geq 20 \mathrm{~mm}^{41}$

\section{SURVEILLANCE}

Due to lack of prospective and controlled data, most of the recommendations and guidelines are based on expert opinion and observational data. Table 3 summarizes the current U.S. Multi-Society Task Force (US MSTF), ${ }^{42}$ European Society of Gastrointestinal Endoscopy (ESGE) ${ }^{43}$ and British Society of Gastroenterology (BSG) position statement guidance on surveillance for serrated polyps (Table 3); however more recently data has become available both on the comparative risk of small and advanced serrated lesions versus adenomas and whether serrated lesions and adenomas should be treated separately or together.

\section{SURVEILLANCE FOR SMALL <10 MM SERRATED LESIONS}

The BSG position statement on serrated polyps in the colorectum recommended no surveillance for patients with one or more serrated lesions $<10 \mathrm{~mm}$ in size who do not meet the criteria for serrated polyposis syndrome (SPS), ${ }^{16}$ although US MSTF guidelines suggests 5 yearly surveillance for 1 to 2 serrated lesions $<10 \mathrm{~mm}$ in size. There are as yet no prospective data to validate this recommendation. Schreiner et al. ${ }^{44}$ report in a U.S. cohort from more than a decade ago, 248 out of 3,121 patients (7.9\%) had at least 1 proximal non-dysplastic serrated polyp (ND-SP). They were more likely than patients with no proximal ND-SP to have advanced neoplasia (17.3\% vs 10.0\%). During surveillance, 39 patients with baseline proximal ND-SP and no neoplasia were more likely to have neoplasia compared with subjects who did not have polyps (odds ratio [OR], 3.14). Among patients with advanced neoplasia at baseline, those with proximal NDSP $(n=43)$ were more likely to have advanced neoplasia during surveillance (OR, 2.17). The United States, pathology based casecontrol study suggested that the rate of CRC was significantly higher in sessile serrated adenomas that in patients with adenomas or hyperplastic polyps over 13 years follow-up (12.5\% vs $1.8 \%$ vs $1.8 \%$, respectively). ${ }^{45}$ All serrated lesions with subsequent cancer were $<10 \mathrm{~mm}$ in size; however some SPS patients and patients with traditional serrated adenomas were included and it is not clear whether SSAs were resected comprehensively and not just biopsied. In a large Danish case-control cohort, which reanalyzed pathological samples using modern definitions of serrated polyps, serrated lesions alone were broadly risk equivalent to adenomas alone for future cancer risk without considering size. ${ }^{46}$ Given that non-advanced serrated lesions appear risk equivalent to non-advanced adenomas, their surveillance should be equivalent, with no surveillance recommended by the BSG position statement or ESGE and that patients should return to population screening.

\section{SURVEILLANCE FOR ADVANCED SERRATED LESIONS (SSL $\geq 10$ MM, SSL WITH DYSPLASIA OR TRADITIONAL SERRATED ADENOMA)}

The BSG position statement on serrated polyps in the colorectal recommends one off surveillance colonoscopy at 3 years for patients with an advanced serrated lesion, defined as a SSL $\geq 10$ $\mathrm{mm}$, SSL with dysplasia and traditional serrated adenomas, ${ }^{16}$ in line with US MSTF recommendation, and broadly with ESGE recommendation (Table 3). No prospective data to validate this recommendation exists; however, a number of lines of evidence are strongly suggestive that future CRC risk is increased by these lesions to a level consistent with that post advanced adenoma detection. In the Norwegian Colorectal Cancer Prevention (NORCCAP) screening study, large $\geq 10 \mathrm{~mm}$ hyperplastic (serrated) lesions were associated with the same future CRC risk as advanced adenomas, increased 3- to 4-fold versus no polyps. ${ }^{47}$ A large Danish cohort which reanalyzed pathological samples using modern definitions of serrated polyps, traditional serrated adenomas and SSL with dysplasia had an almost 5-fold higher risk of future CRC. ${ }^{46}$

Table 3. US MSTF, ESGE and BSG Recommendations for the Surveillance of Sessile Serrated Polyps

\begin{tabular}{lccc}
\hline \multicolumn{1}{c}{ Baseline colonoscopy finding } & \multicolumn{2}{c}{ Recommended surveillance interval } \\
\cline { 2 - 4 } & US MSTF & ESGE & No surveillance on the basis of serrated polyps \\
\hline Size $<10 \mathrm{~mm}$ without dysplasia & $5 \mathrm{yr}$ & $3 \mathrm{yr}$ & One off colonoscopy at $3 \mathrm{yr}$ \\
Any lesion $\geq 10 \mathrm{~mm}$ in size or with dysplasia & $3 \mathrm{yr}$ & $3 \mathrm{yr}$ & One off colonoscopy at $3 \mathrm{yr}$ \\
Or traditional serrated adenoma & $1 \mathrm{yr}$ & $3 \mathrm{yr}$ genetic counselling & 1-2 yr once colon cleared consider genetic counselling \\
Serrated Polyposis syndrome & &
\end{tabular}

US MSTF, U.S. Multi-Society Task Force; ESGE, European Society of Gastrointestinal Endoscopy; BSG, British Society of Gastroenterology. 


\section{SERRATED POLYPOSIS SYNDROME SURVEILLANCE}

SPS is common in bowel cancer screening programs which use guaiac fecal occult blood testing (gFOBT) or fecal immunochemical testing (FIT) as a screening test, with estimates of SPS prevalence ranging from 1:150 to $1: 300 .^{48,49}$ A recent Spanish FIT based cohort followed up all their patients with proximal serrated polyps, tripling the number of additional cases of SPS, for a final prevalence of $1: 100 .^{50}$ Therefore, especially when using FIT in bowel cancer screening, colonoscopists should be alert to a diagnosis of SPS.

US MSTF and ESGE recommend surveillance period of 1 year and 3 years respectively (Table 3).The BSG position statement on serrated polyps in the colorectal recommended 1 to 2 yearly surveillance for patients meeting the World Health Organization (WHO) criteria for SPS. ${ }^{16}$ This recommendation was on the basis that in early cohorts, future risk of CRC was elevated at as much as $7 \%$ at 5 years; ${ }^{51,52}$ however in larger cohorts with rigorous surveillance performed every 1 to 2 years, with all lesions larger than $5 \mathrm{~mm}$ in size resected, at academic centers, the risk appeared much lower with CRC only diagnosed at 1.9 cases per 1,000 years of patient follow-up. ${ }^{53,54}$ Recent data suggests once the colon is cleared, follow-up can be safely deferred to 2 years. ${ }^{55,56}$

The risk for patient who are first-degree relatives of patients with SPS also appears elevated between 3- to 5-fold compared to the general population ${ }^{51,57,58}$ and screening colonoscopy is recommended for this group, with subsequent colonoscopies determined by polyp burden. Surveillance should then be performed every 5 years if no polyps are found.

A recent paper that looked at patients with multiple serrated polyps and adenomas, not quite meeting the criteria for SPS also noted that their risk for CRC was equivalent to patients who met the WHO definition of SPS, and that their first-degree relatives also had an elevated risk of CRC, comparable to the risk for first-degree relatives of SPS patients. ${ }^{58}$

\section{SURVEILLANCE WHEN SERRATED LESIONS AND AD- ENOMAS ARE FOUND TOGETHER}

In previous guidelines it was not possible to comment on how to assign surveillance intervals when serrated lesions occurred together with adenomas and whether risk, and therefore surveillance intervals, should be considered separately for each polyp class or if their risk was additive. At that time, each polyp class was considered separately and the shortest surveillance interval was used. ${ }^{16}$ There has been recent data on the future risk when adenomas and serrated lesions are found together. The risk of finding an advanced adenoma at surveillance had an OR for future risk with synchronous advanced adenomas and serrated lesions at index exam 4-fold higher than for advanced adenomas alone. A further similar study from Korea presented in abstract form suggests additive risk between adenomas and SSL with the risk of advanced colorectal neoplasia at 3 years follow-up for adenoma with synchronous serrated polyp being $17.9 \%$ versus $10.7 \%$ for adenoma alone $(p<0.001) .^{59}$ Audit data from an Australian CRC surveillance program with 2,157 patient followed up for a median of 50 months found additive risk of advanced neoplasia when serrated lesion and adenomas were found together (high-risk adenoma: hazard ratio [HR]=2.04 [95\% CI, 1.70 to 2.45]; high-risk SSP+adenoma: $\mathrm{HR}=3.20$ [95\% CI 1.31 to 7.82 ]; low-risk SSP+adenoma: $\mathrm{HR}=2.20$ [95\% CI, 1.03 to 4.68]). ${ }^{60}$ Older data from the 1990s when serrated lesions were less recognised both endoscopically and pathologically is supportive but less definitive.

\section{CONCLUSION}

Adequate resection technique and appropriate surveillance of serrated polyps is of utmost importance as they are a major reason behind interval cancers and failure of screening colonoscopy in preventing right sided colon cancers. Their identification is difficult and challenging but is aided by increased withdrawal time and chromoendoscopy. Cold resection techniques are safe and effective and are increasingly supported by larger cases series data. Surveillance strategies, on the other hand, are currently predominantly based on expert opinion and observational data; however new case series are becoming available to make these recommendations more evidence based.

\section{CONFLICTS OF INTEREST}

No potential conflict of interest relevant to this article was reported.

\section{ACKNOWLEDGEMENTS}

J.E.E. was funded by the National Institute for Health Research (NIHR) Oxford Biomedical Research Centre (BRC). The views expressed are those of the author(s) and not necessarily those of the NHS, the NIHR or the Department of Health.

\section{ORCID}

Vipin Gupta

https://orcid.org/0000-0002-9620-1696

James E. East

https://orcid.org/0000-0001-8035-3700

\section{REFERENCES}

1. Bray F, Ferlay J, Soerjomataram I, Siegel RL, Torre LA, Jemal A. Global cancer statistics 2018: GLOBOCAN estimates of incidence and mortality worldwide for 36 cancers in 185 countries. CA Cancer J Clin 2018;68:394-424.

2. Snover DC. Update on the serrated pathway to colorectal carci- 
noma. Hum Pathol 2011:42:1-10.

3. Lee CK, Kim YW, Shim JJ, Jang JY. Prevalence of proximal serrated polyps and conventional adenomas in an asymptomatic average-risk screening population. Gut Liver 2013;7:524-531.

4. Min YW, Lee JH, Lee SH, et al. Prevalence of proximal colon serrated polyps in a population at average risk undergoing screening colonoscopy: a multicenter study. Clin Res Hepatol Gastroenterol 2012;36:604-608.

5. Leung WK, Tang V, Lui PC. Detection rates of proximal or large serrated polyps in Chinese patients undergoing screening colonoscopy. J Dig Dis 2012;13:466-471.

6. Cooper GS, Xu F, Barnholtz Sloan JS, Schluchter MD, Koroukian SM. Prevalence and predictors of interval colorectal cancers in medicare beneficiaries. Cancer 2012;118:3044-3052

7. Singh H, Nugent Z, Demers AA, Kliewer EV, Mahmud SM, Bernstein $\mathrm{CN}$. The reduction in colorectal cancer mortality after colonoscopy varies by site of the cancer. Gastroenterology 2010;139:1128-1137.

8. Kahi CJ, Hewett DG, Norton DL, Eckert GJ, Rex DK. Prevalence and variable detection of proximal colon serrated polyps during screening colonoscopy. Clin Gastroenterol Hepatol 2011;9:42-46.

9. Pohl H, Srivastava A, Bensen SP, et al. Incomplete polyp resection during colonoscopy-results of the complete adenoma resection (CARE) study. Gastroenterology 2013;144:74-80.

10. Rex DK, Ahnen DJ, Baron JA, et al. Serrated lesions of the colorectum: review and recommendations from an expert panel. Am J Gastroenterol 2012;107:1315-1329.

11. Bouwens MW, van Herwaarden YJ, Winkens B, et al. Endoscopic characterization of sessile serrated adenomas/polyps with and without dysplasia. Endoscopy 2014;46:225-235.

12. Hazewinkel Y, López-Cerón M, East JE, et al. Endoscopic features of sessile serrated adenomas: validation by international experts using high-resolution white-light endoscopy and narrow-band imaging. Gastrointest Endosc 2013;77:916-924.

13. East JE, Vieth M, Rex DK. Serrated lesions in colorectal cancer screening: detection, resection, pathology and surveillance. Gut 2015;64:991-1000

14. Ma MX, Bourke MJ. Sessile serrated adenomas: how to detect, characterize and resect. Gut Liver 2017;11:747-760.

15. Roelandt P, Demedts I, Willekens H, et al. Impact of endoscopy system, high definition, and virtual chromoendoscopy in daily routine colonoscopy: a randomized trial. Endoscopy 2019;51:237243.

16. East JE, Atkin WS, Bateman AC, et al. British Society of Gastroenterology position statement on serrated polyps in the colon and rectum. Gut 2017;66:1181-1196.

17. Hurt C, Ramaraj R, Farr A, et al. Feasibility and economic assessment of chromocolonoscopy for detection of proximal serrated neoplasia within a population-based colorectal cancer screening programme (CONSCOP): an open-label, randomised controlled non-inferiority trial. Lancet Gastroenterol Hepatol 2019;4:364375.
18. Repici A, Wallace MB, East JE, et al. Efficacy of per-oral methylene blue formulation for screening colonoscopy. Gastroenterology 2019;156:2198-2207.

19. Baek MD, Jackson CS, Lunn J, et al. Endocuff assisted colonoscopy significantly increases sessile serrated adenoma detection in veterans. J Gastrointest Oncol 2017;8:636-642.

20. Shirin H, Shpak B, Epshtein J, et al. G-EYE colonoscopy is superior to standard colonoscopy for increasing adenoma detection rate: an international randomized controlled trial (with videos). Gastrointest Endosc 2019;89:545-553.

21. Rex DK, Clodfelter R, Rahmani F, et al. Narrow-band imaging versus white light for the detection of proximal colon serrated lesions: a randomized, controlled trial. Gastrointest Endosc 2016;83:166171.

22. Atkinson NSS, Ket $S$, Bassett $P$, et al. Narrow-band imaging for detection of neoplasia at colonoscopy: a meta-analysis of data from individual patients in randomized controlled trials. Gastroenterology 2019;157:462-471.

23. IJspeert JE, Bastiaansen BA, van Leerdam ME, et al. Development and validation of the WASP classification system for optical diagnosis of adenomas, hyperplastic polyps and sessile serrated adenomas/polyps. Gut 2016;65:963-970.

24. Zawaly K, Rumbolt C, Abou-Setta AM, et al. The efficacy of splitdose bowel preparations for polyp detection: a systematic review and meta-analysis. Am J Gastroenterol 2019;114:884-892.

25. Repici A, Hassan C, Vitetta E, et al. Safety of cold polypectomy for $<10 \mathrm{~mm}$ polyps at colonoscopy: a prospective multicenter study. Endoscopy 2012;44:27-31.

26. Lee CK, Shim JJ, Jang JY. Cold snare polypectomy vs. Cold forceps polypectomy using double-biopsy technique for removal of diminutive colorectal polyps: a prospective randomized study. Am J Gastroenterol 2013;108:1593-1600.

27. Horiuchi A, Hosoi K, Kajiyama M, Tanaka N, Sano K, Graham DY. Prospective, randomized comparison of 2 methods of cold snare polypectomy for small colorectal polyps. Gastrointest Endosc 2015;82:686-692.

28. Din S, Ball AJ, Riley SA, Kitsanta P, Johal S. Cold snare polypectomy: does snare type influence outcomes? Dig Endosc 2015;27:603-608.

29. Nanda KS, Tutticci N, Burgess N, Sonson R, McLeod D, Bourke MJ. Caught in the act: endoscopic characterization of sessile serrated adenomas with dysplasia. Gastrointest Endosc 2014;79:864870.

30. Rao AK, Soetikno R, Raju GS, et al. Large sessile serrated polyps can be safely and effectively removed by endoscopic mucosal resection. Clin Gastroenterol Hepatol 2016;14:568-574.

31. Pellise M, Burgess NG, Tutticci N, et al. Endoscopic mucosal resection for large serrated lesions in comparison with adenomas: a prospective multicentre study of 2000 lesions. Gut 2017;66:644653.

32. Burgess NG, Metz AJ, Williams SJ, et al. Risk factors for intraprocedural and clinically significant delayed bleeding after wide-field 
endoscopic mucosal resection of large colonic lesions. Clin Gastroenterol Hepatol 2014;12:651-661.

33. Cha JM, Lim KS, Lee SH, et al. Clinical outcomes and risk factors of post-polypectomy coagulation syndrome: a multicenter, retrospective, case-control study. Endoscopy 2013;45:202-207.

34. Tate DJ, Awadie H, Bahin FF, et al. Wide-field piecemeal cold snare polypectomy of large sessile serrated polyps without a submucosal injection is safe. Endoscopy 2018;50:248-252.

35. Rameshshanker R, Tsiamoulos Z, Latchford A, Moorghen M, Saunders BP. Resection of large sessile serrated polyps by cold piecemeal endoscopic mucosal resection: Serrated COld Piecemeal Endoscopic mucosal resection (SCOPE). Endoscopy 2018;50:E165E167.

36. Piraka C, Saeed A, Waljee AK, Pillai A, Stidham R, Elmunzer BJ. Cold snare polypectomy for non-pedunculated colon polyps greater than 1cm. Endosc Int Open 2017;5:E184-E189.

37. Kondo S, Mori H, Nishiyama N, et al. Case of pediatric traditional serrated adenoma resected via endoscopic submucosal dissection. World J Gastroenterol 2017;23:4462-4466.

38. Repici A, Hassan C, Pagano N, et al. High efficacy of endoscopic submucosal dissection for rectal laterally spreading tumors larger than $3 \mathrm{~cm}$. Gastrointest Endosc 2013;77:96-101.

39. Draganov PV, Wang AY, Othman MO, Fukami N. AGA Institute clinical practice update: endoscopic submucosal dissection in the United States. Clin Gastroenterol Hepatol 2019;17:16-25.

40. Ferlitsch M, Moss A, Hassan C, et al. Colorectal polypectomy and endoscopic mucosal resection (EMR): European Society of Gastrointestinal Endoscopy (ESGE) Clinical Guideline. Endoscopy 2017;49:270-297.

41. Kim KH, Kim KO, Jung Y, et al. Clinical and endoscopic characteristics of sessile serrated adenomas/polyps with dysplasia/ adenocarcinoma in a Korean population: a Korean Association for the Study of Intestinal Diseases (KASID) multicenter study. Sci Rep 2019;9:3946.

42. Lieberman DA, Rex DK, Winawer SJ, Giardiello FM, Johnson DA, Levin TR. Guidelines for colonoscopy surveillance after screening and polypectomy: a consensus update by the US Multi-Society Task Force on Colorectal Cancer. Gastroenterology 2012;143:844857.

43. Hassan C, Quintero E, Dumonceau JM, et al. Post-polypectomy colonoscopy surveillance: European Society of Gastrointestinal Endoscopy (ESGE) Guideline. Endoscopy 2013;45:842-851.

44. Schreiner MA, Weiss DG, Lieberman DA. Proximal and large hyperplastic and nondysplastic serrated polyps detected by colonoscopy are associated with neoplasia. Gastroenterology 2010;139:1497-1502.

45. Lu FI, van Niekerk de W, Owen D, Tha SP, Turbin DA, Webber DL. Longitudinal outcome study of sessile serrated adenomas of the colorectum: an increased risk for subsequent right-sided colorectal carcinoma. Am J Surg Pathol 2010;34:927-934.

46. Erichsen R, Baron JA, Hamilton-Dutoit SJ, et al. Increased risk of colorectal cancer development among patients with serrated polyps. Gastroenterology 2016;150:895-902.

47. Holme Ø, Bretthauer M, Eide TJ, et al. Long-term risk of colorectal cancer in individuals with serrated polyps. Gut 2015;64:929-936.

48. Biswas S, Ellis AJ, Guy R, Savage H, Madronal K, East JE. High prevalence of hyperplastic polyposis syndrome (serrated polyposis) in the NHS bowel cancer screening programme. Gut 2013;62:475.

49. Moreira L, Pellisé M, Carballal S, et al. High prevalence of serrated polyposis syndrome in FIT-based colorectal cancer screening programmes. Gut 2013;62:476-477.

50. Rivero-Sanchez L, Lopez-Ceron M, Carballal S, et al. Reassessment colonoscopy to diagnose serrated polyposis syndrome in a colorectal cancer screening population. Endoscopy 2017;49:44-53.

51. Boparai KS, Mathus-Vliegen EM, Koornstra JJ, et al. Increased colorectal cancer risk during follow-up in patients with hyperplastic polyposis syndrome: a multicentre cohort study. Gut 2010;59:1094-1100.

52. Edelstein DL, Axilbund JE, Hylind LM, et al. Serrated polyposis: rapid and relentless development of colorectal neoplasia. Gut 2013;62:404-408.

53. Carballal S, Rodríguez-Alcalde D, Moreira L, et al. Colorectal cancer risk factors in patients with serrated polyposis syndrome: a large multicenter study. Gut 2016;65:1829-1837.

54. IJspeert JE, Rana SA, Atkinson NS, et al. Clinical risk factors of colorectal cancer in patients with serrated polyposis syndrome: a multicentre cohort analysis. Gut 2017;66:278-284.

55. MacPhail ME, Thygesen SB, Patel N, Broadley HM, Rex DK. Endoscopic control of polyp burden and expansion of surveillance intervals in serrated polyposis syndrome. Gastrointest Endosc 2019;90:96-100.

56. Bleijenberg AG, IJspeert JE, van Herwaarden YJ, et al. Personalised surveillance for serrated polyposis syndrome: results from a prospective 5-year international cohort study. Gut 2020;69:112121.

57. Win AK, Walters RJ, Buchanan DD, et al. Cancer risks for relatives of patients with serrated polyposis. Am J Gastroenterol 2012;107:770-778.

58. Egoavil C, Juárez M, Guarinos C, et al. Increased risk of colorectal cancer in patients with multiple serrated polyps and their firstdegree relatives. Gastroenterology 2017;153:106-112.

59. Park SK, Kim HS, Yang HJ, et al. Coexistent adenoma and serrated polyps on index colonoscopy and the risk of metachronous advanced colorectal neoplasia. Endosc Int Open 2019;7:E1748E1754.

60. Symonds E, Anwar S, Young G, et al. Sessile serrated polyps with synchronous conventional adenomas increase risk of future advanced neoplasia. Dig Dis Sci 2019;64:1680-1685. 